\title{
A “Switching Costs" Approach: EPA's Clean Power Plan as a Model for Allocating the Burden of Carbon Reductions Among Nations
}

\author{
MICHAEL BARSA* \\ DAVID DANA**
}

\section{TABLE OF CONTENTS}

I. Past And CuRrent Allocation Regimes ..............................................

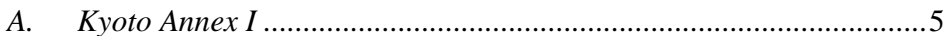

B. The European Union's ETS ......................................................6

1. ETS Phases I and II-Individual Wealth Allocation ....................7

2. ETS Phase III-Collective Allocation ........................................8

3. Non-ETS/Effort Sharing Decision.............................................

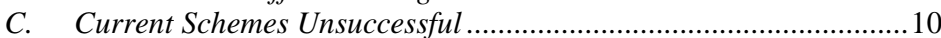

II. Proposed And Possible Future Allocation Regimes............................11

A. Equal Emissions Per Capita, Emissions Based on

Historical Contribution to Climate Change, and

Emissions Based on GNP or GNP Per Capita.................................11

B. Allocation Based on Net Welfare Benefits of Emissions

Reductions and Climate Change Mitigation ....................................13

C. Other Possible Schemes .................................................................14

III. A COST-SENSITIVE ApPROACH............................................................ 14

A. The Traditional Cost-Conscious Model .........................................15

B. EPA's Clean Power Plan Considers Costs Differently ......................18

* C 2016 Michael Barsa. Senior Lecturer, Co-Director of the Environmental Law Concentration, Northwestern University School of Law. J.D., Stanford University; M.A., Stanford University; B.A., Stanford University.

** (C) 2016 David Dana. Kirkland \& Ellis Professor of Law, Northwestern University School of Law. J.D., Harvard University; B.A., Harvard University. 
IV. APPLYING A COST-SENSITIVE MOdEL TO THE INTERNATIONAL

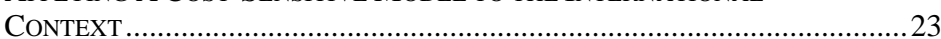

A. The Advantages of a Cost-Sensitive Approach..................................24

1. Facilitating Agreement .............................................................24

2. Resonating with a Message of Unity ............................................25

B. $\quad$ Do the Advantages Apply Outside the U.S. ?...................................26

C. Disadvantages of a Switching Costs Approach.....................................2

D. Mitigating Perverse Incentives .....................................................28

E. The Broad View - Many Ways Differentiate ....................................29

One of the most pressing international environmental issues today is how to allocate the burden of achieving carbon reductions among nations. One superficially appealing approach-adopted in part by the Kyoto Protocol and the EU's European Trading System-is to require that each nation reduce its aggregate annual emissions by an equal percentage. Other approaches, including the one adopted in later phases of the European Trading System, require reductions in emissions according to the relative wealth of each nation. Still other approaches that have been discussed include requiring each nation to reduce per capita (as opposed to aggregate) emissions by an equal percentage.

None of these approaches, however, has provided a workable system of emissions reductions that appears capable of garnering worldwide acceptance. In this Article we explore another option, one roughly modeled on the United States Environmental Protection Agency's Clean Power Rule. In the proposed Clean Power Rule, EPA was required to allocate the burden of reducing carbon emissions from electricity production among the States. EPA chose a novel approach that is quite different from that adopted in Kyoto or the EU—what we call a "Switching Costs" approach. Under this approach, each State is allocated reduction percentages in emissions rates or mass emissions that depend heavily on the State's switching opportunitiesits opportunities to switch from coal to natural gas and from fossil-fuel energy sources to renewable energy. In states in which switching opportunities are relatively abundant, and hence transition costs relatively low, higher percentage reductions in emission rates per megawatt or mass emissions are required. One result is that increases in electricity rates in the State should be more similar, closer to equal, than they would be under an approach that required emissions reductions without regard to variations in the switching opportunities available to each State. Thus, as Bob Sussman reported, EPA's analysis of its proposed Rule's effects on rates in twenty different regions within the United States suggested that rates will "vary somewhat" 
but "these variations are fairly small, generally within 2 percent below or above the national average in $2030^{1}$

The final EPA rule seems to limit the range in state targets and perhaps reduce the extent of variation in state targets based on the differences in switching opportunities available to each state. For example, Arizona, which has readily available solar alternatives, faced a much higher target under the proposed plan than the final rule. On the other hand, Kentucky, which is coal-dependent and has little in the way of an infrastructure to allow a ready shift to natural gas or renewables, faced a much lower target under the proposed plan than under the final rule. Moreover, EPA does not appear to have released an analysis of how much the final rule, as opposed to the proposed one, will affect electricity rates in different regions of the United States; EPA seems to suggest that the final rule has so much flexibility built into it that costs cannot be predicted on a state-by-state basis. It is possible that there will be more substantial variation in ratepayer costs across the country as a result of the EPA final rule than under the proposed rule.

Nonetheless, we can use the EPA Rule as an approach to allocation of carbon reductions among the member states or nations to a multilateral agreement that is based on the relative availability and hence relative costs to each participant of switching from a high-emission fossil fuel to a lower-emission one and/or switching power production to renewable sources. Nations for whom switching would be relatively less expensive would be required to reduce emissions more (either in terms of the emissions rate per megawatt or in terms of mass emissions) than nations for whom switching would be relatively more expensive. Focusing on the availability of switching opportunities and hence the costs of emission reductions to ratepayers as the measure for what constitutes an "equal" or "fair" burden among states or nations has several normative and political feasibility advantages over other approaches. Just as when a group of diners agree to split a bill for a large dinner in which each diner ordered different items with somewhat different prices and each diner has a different economic situation, allocation emissions reductions based on an equal ratepayer costs or something close to it avoids normatively intractable arguments about how much each state or nations' population is ethically responsible for

1. Bob Sussman, Debating the EPA's Clean Power Plan Proposal-EPA's State Goals for Reducing Carbon Pollution from Power Plants: A Thoughtful and Fair Solution, Brookings: The Planet Policy (Aug. 18, 2014, 2:00 PM), http://www.brookings.edu/ blogs/planetpolicy/posts/2014/08/18-debating-epa-clean-power-proposal. 
its historic emissions (as opposed to current ones) and how much differences in wealth should translate into differences in ethical obligations with regard to efforts to address common problem. Everyone puts in roughly the same amount to the pot. And because as a political reality those states or nations that have relatively few switching opportunities and hence relatively high switching costs are likely to be much more politically resistant to ambitious emissions targets than those that have ample switching opportunities and relatively low switching costs, this approach may be more politically acceptable than those that have been tried to date.

However, one potential downside is that the switching opportunities approach may create a disincentive for a state (or nation) to create more opportunities for transitioning to low- or zero-emission power sources, because such efforts could result in the state (or nation) being allocated a higher emission reductions target in the next round of targets, which, if nothing else, reduces its flexibility as to future energy-related and economic decisions. Switching costs are in part the product of factors outside of direct political control - how much sun or wind that is available to a given jurisdiction is in part a product of geography - but they are also a product of political decisions regarding public investments and incentives for private investments in energy production infrastructure. There are, however, ways to deal with such disincentives that make the switching opportunities approach a promising model for international accords. Indeed, EPA took a step in this direction in the Final Rule by offering credit awards to states that quickly create renewable generation capacity.

Allocations of emissions reductions (either in terms of rate per megawatt or by mass) in terms of switching opportunities and switching costs might be a less appealing and less compelling idea in a regime in which there is highly effective tradable-permit or carbon tax regime. In an ideal tradable permit regime and an ideal carbon tax regime, we would expect to see the largest reductions in emissions in places in which the costs of reducing carbon emissions by whatever means are available are lowest, and that would imply that, at least among otherwise similar jurisdictions (notably, jurisdictions with comparable efficiency levels at emitting facilities and comparable demand-side conservation or efficiency), we would expect to see greater reductions in those where switching costs were relatively low. However, the transaction costs and political economy problems surrounding $\mathrm{CO}_{2}$ cap-and-trade regimes have been much discussed, as have the institutional design and political feasibility problems of carbon taxes. In the United States, for example, any hint of an explicit carbon tax has been disavowed by political leaders, and Australia recently repealed its carbon tax. It may well be that an agreement based on a switching-costs-sensitive initial allocation of emissions reduction obligations could have the political traction to actually be adopted, and, once adopted, trading and taxing carbon could 
be added as an overlay to further reduce costs of emissions reductions. But even so, beginning with a switching-cost-sensitive allocation may be necessary to move to a workable trading or tax regime. In this account, a switching-costs-sensitive-allocation is the second-best regime that may allow for the realization of the first-best regime.

In Part I, this paper reviews the allocation plans that have been tried so far on an international scale and why they have not succeeded. In Part II, the paper explains EPA's Clean Power Rule and what we are calling the switching opportunities approach that is at least roughly suggested by the Rule. In Part III, the paper discusses the two different "cost-sensitive" approaches adopted by the EPA under the Clean Air Act so far, and in Part IV, the paper discusses the basis for using the Clean Power Plan as a model and the advantages and disadvantages of "scaling up" the switching opportunities approach to the international arena.

\section{PASt AND CURRENT AlLOCATION REgIMES}

\section{A. Kyoto Annex I}

In 1982, the United Nations Framework Convention on Climate Change (UNFCC) first established an international system for addressing climate change by nation-states and also established the principle that nations ought to stabilize greenhouse gas emissions (GHGs) "at a level that would prevent dangerous anthropogenic interference with the climate system."2 However, there were no binding emissions reductions commitments in the UNFCC itself. It wasn't until 1997 that the Kyoto Protocol to the UNFCC sets binding emissions reductions commitments for developed countries (listed in Annex 1 to the UNFCC) to be met during the period of 2008 to 2012. ${ }^{3}$ These reductions were spelled-out for each Annex 1 country in Annexes A and B of the Kyoto Protocol, and together were designed "to reduc[e] their overall emissions of [greenhouse] gases by at least 5 percent below 1990 levels in the commitment period 2008 to 2012." ${ }^{4}$ For most developed countries, this required the same emissions reduction, namely to $92 \%$ of

2. See U.N. Framework CONVEnTION On Climate Change 2, June 3, 1992, Treaty Doc. No. 102-38, 1771 U.N.T.S. 107, U.N. Docs. (1992), http://unfccc.int/resource/docs/ convkp/conveng.pdf.

3. See Kyoto Protocol to the United Nations Framework Convention on Climate Change, art. 3, Dec. 10 1997, U.N. Docs FCCC/CP1997/L.7/Add.1 (1998), http://unfccc.int/resource/docs/convkp/kpeng.pdf, 37 I.L.M. 22 [hereinafter Kyoto Protocol].

4. See Kyoto Protocol, supra note 3, at art. 3.1. 
1990 levels by the end of the commitment period (or a roughly $8 \%$ reduction in GHG emissions), while some of the less developed or newly independent former Soviet states were given higher targets. ${ }^{5}$ Developing countries, most notably China, were not on the list of nations required to reduce emissions. ${ }^{6}$

On its face, then, this first approach requires roughly equal emissions reductions by the most developed countries. However, the Kyoto Protocol also provides for so-called flexibility mechanisms that might lead to fewer (or more) emissions reductions in each nation itself. For example, Article 6 of the Protocol provides for "joint implementation," which "allows a country with an emission reduction or limitation commitment under the Kyoto Protocol (Annex B Party) to earn emission reduction units (ERUs) from an emission-reduction or emission removal project in another Annex B Party, each equivalent to one tone of $\mathrm{CO} 2$, which can be counted towards meeting its Kyoto target." 7 Similarly, Article 17 of the Protocol allows for Emissions Trading, which "allows countries that have emission units to spare —emissions permitted them but not "used" - to sell this excess capacity to countries that are over their targets." ${ }^{8}$ And Article 12 establishes the so-called Clean Development Mechanism, which "allows a country with an emission-reduction or emission-limitation commitment under the Kyoto Protocol (Annex B Party) to implement an emission-reduction project in developing countries. Such projects can earn saleable certified emission reduction (CER) credits, each equivalent to one tonne of CO2, which can be counted towards meeting Kyoto targets."9

Nonetheless, despite these flexibility mechanisms, the basic principle under the Kyoto Protocol remains the same. The most developed countries must reduce emissions by roughly equal amounts. The only flexibility is in whether those emissions reductions take place within the country or outside it.

\section{B. The European Union's ETS}

Following the Kyoto Protocol, the European Union (EU) instituted an emissions trading system (ETS) in order to fulfill its member states'

5. Id. at Annex B.

6. Id.

7. See U.N. Framework Convention on Climate Change, Куото Protocol: MECHANISM: JOINT IMPLEMENTATION, http://unfccc.int/kyoto_protocol/mechanisms/joint implementation/ items/1674.php; see also Kyoto Protocol, supra note at 3, art. 6.

8. See U.N. Framework Convention on Climate Change, Kуото Protocol: MECHANISM: INTERNATIONAL EMISSION TRAINING, http://unfccc.int/kyoto_protocol/mec hanisms/emissions_trading/items/2731.php.

9. See U.N. Framework Convention on Climate Change, Куото Protocol: Mechanism: Clean Development Mechanism, http://unfccc.int/kyoto_protocol/ mechanisms/clean_development_mechanism/items/2718.php. 
obligations under the treaty. Under the ETS, the EU employed two different methods of allocating responsibility for controlling GHGs. First, the EU adopted a system that allocated responsibility according to the individual country's wealth. Then, as the Kyoto commitment period ended, the EU adopted a system that allocated responsibility collectively. Finally, the EU also adopted mandatory annual emissions targets for sectors not covered by ETS.

\section{ETS Phases I and II-Individual Wealth Allocation}

As an Annex I party to the Kyoto Protocol, the European Community and its 15 Member States at the time of ratifying the Protocol agreed to reduce GHG emissions by at least 8\% below 1990 levels during the "commitment period" of 2008 to 2012. ${ }^{10}$ By signing on as a collective entity, the EU took the first step in setting up a "cap and trade” system among its Member States. The basic structure of such a system entails establishing an overall limit, or cap, on GHG emissions, granting facilities that emit GHGs allowances for each ton of carbon dioxide (or equivalent) that they emit, and giving the business that control these facilities one of three main options. They can emit as much carbon dioxide as they have allowances, emit less and trade their excess allowances, or emit more and purchase excess allowances. By reducing the number of total allowances each year and penalizing businesses for non-compliance, total emissions decline, while businesses are incentivized to invest in emission-reducing capital projects. ${ }^{11}$

The EU administered this program through its ETS. In preparation for the Kyoto commitment period, the EU created a preliminary first phase which functioned as a pilot program for testing out this new cap and trade system, while the second phase coincided with the commitment period from 2008 to 2012. ${ }^{12}$ The EU further allocated responsibility for the 8\% reduction among its Member States based on relative wealth. ${ }^{13}$ For example,

10. United Nations Framework Convention on Climate Change, Kyoto Protocol Reference MANuAl on ACCOUNTING of EMISSIONS AND AsSigned AMOUNT 13 (2008), https://unfccc.int/resource/docs/publications/08_unfccc_kp_ref_manual.pdf.

11. Allowances and Caps, EUROPEAN COMM'N, http://ec.europa.eu/clima/policies/ ets/cap/index_en.htm (last updated Apr. 21, 2016).

12. EU ETS 2005-2012, EUROPEAN COMM'N, http://ec.europa.eu/clima/polici es/ets/pre2013/index_en.htm (last updated Feb. 11, 2016).

13. Kyoto emissions targets: Joint fulfillment, 'burden sharing' and base years, EUROPEAN COMM’n, https://web.archive.org/web/20150703071343/http://ec.europa.eu/clima/ policies/g-gas/kyoto/index_en.htm (last updated May. 8, 2015). 
the nation with the highest GDP per capita, Luxembourg, had to reduce its emissions by $28 \%$ vs. 1990 levels, whereas Portugal as the poorest of the 15 was allowed to increase its emissions by $27 \%{ }^{14}$ With caps in place for each individual country, each Member State submitted National Allocation Plans (NAPs) that provided detailed emissions information for each GHG-emitting facility, or "installation" covered by the Kyoto Protocol—mainly power generators and energy-intensive industrial sectors - within its borders. ${ }^{15}$ The EU subsequently reviewed the NAPs and granted the appropriate number of allowances to individual installations so that Member States met their individual reduction targets. ${ }^{16}$ Thus, by signing onto Kyoto as a collective entity, the EU created a system that redistributed individual nations' responsibilities for climate change based on wealth relative to fellow Member States.

\section{ETS Phase III-Collective Allocation}

As the Kyoto commitment period ended and follow-on international climate change negotiations stalled, the EU continued the ETS program, with some modifications to increase its effectiveness. ${ }^{17}$ Phase III, which started in 2013, maintained the basic structure of the system, but eliminated caps for individual countries. ${ }^{18}$ Instead, the EU established a single cap to cover the entire Union, which decreases over the course of Phase III, such that 2020 emissions will be $21 \%$ lower than 2005 levels. ${ }^{19}$ The responsibility to reduce emissions then falls directly upon individual GHG-emitting installations to reduce emissions each year, or purchase a sufficient number of allowances via the cap-and-trade system to cover actual emissions. ${ }^{20}$ Thus, Member States are effectively bypassed in allocating responsibility, as an installation that emits 1,000 tons of carbon dioxide in Luxembourg will be treated exactly the same as an installation that emits 1,000 tons of

14. Id.

15. National allocation plans, EUROPEAN COMM'N, http://ec.europa.eu/clima/policies/ ets/pre2013/nap/index_en.htm (last updated Feb. 11, 2016).

16. Id.

17. See generally United Nations Framework Convention on Climate Change, Status of the Doha Amendment, http://unfccc.int/kyoto_protocol/doha_amendment/items/7362.php (last updated May 28, 2015).

18. Allowances and Caps, European COMM’n, supra note 11.

19. The cap set in 2013 was $2,084,301,856$ allowances, decreasing by $1.74 \%$ linearly each year through 2020. Id. The EU changed the reference year for climate change objectives from 1990 to 2005 because the wealth of data collected in 2005 provides the most transparent method to measure progress. Questions and Answers on the Effort Sharing Decision (October 2013), EUROPEAN COMM’N, http://ec.europa.eu/clima/policies/effort/ faq_en.htm (last updated Apr. 15, 2016).

20. Allowances and Caps, EuROPEAN COMM'N, supra note 11. 
carbon dioxide in Portugal. This system therefore treats Member States as equals, restricting emissions activity only to the extent that a Member State has GHG-emitting facilities within its borders.

As an alternative view, this approach also allocates responsibility among Member States based on their relative income levels. Assuming richer states to have more GHG-emitting facilities within its borders as a reflection of more extensive industrialization, while poorer, less industrialized nations will have fewer GHG-emitting facilities, Phase III effectively requires richer states to bear more of the burden of reducing emissions than poorer states. While this approach is quite different from that of Phases I and II - namely because individual facilities are treated exactly the same in Phase III regardless of location within the EU—it still promulgates sharing responsibility based on some variation of relative income levels.

\section{Non-ETS/ Effort Sharing Decision}

Since that ETS only covers approximately half of all GHG emissions, EU Member States adopted mandatory annual emissions targets for sectors not covered by ETS under the Effort Sharing Decision. ${ }^{21}$ Similar to the approach in ETS Phases I and II, the Effort Sharing Decision establishes caps for each Member State based on their relative GDP, with rich countries required to decrease emissions while granting poorer countries the flexibility to increase emissions. ${ }^{22}$ In particular, the Decision establishes limits for annual GHG emissions in 2020 compared to 2005 levels based on a Member State's GDP per capita relative to the EU average. ${ }^{23}$ Countries with GDP per capita higher than the average must reduce their emissions by up to $20 \%$, while nations lower than the average may increase their emissions up to $20 \%{ }^{24}$ In the aggregate, these restrictions should reduce EU-wide

21. ETS Phase III covered less than half of all emissions, including carbon dioxide from power and heat generation, energy-intensive sectors, and commercial aviation; nitrous oxide from production of nitric, adipic, glyoxal and glyoxlic acids; and perfluorocarbons from aluminum production. Sectors not covered by ETS include transport (excluding aviation), buildings, agriculture, and waste sectors, which collectively account for $55 \%$ to $60 \%$ of all EU emissions. Effort Sharing Decision, EUROPEAN COMM’n, http://ec.europa.eu/clima/ policies/effort/index_en.htm (last updated Apr. 15, 2016).

22. Id.

23. Decision No. 406/2009/EC of the European Parliament and of the Council of 23 April 2009 on the effort of Member States to reduce their greenhouse gas emissions to meet the Community's greenhouse gas emission reduction commitments up to 2020, 2009 O.J. (L 140/136).

24. Id. 
emissions in non-ETS sectors by $10 \%$ compared to 2005 levels. ${ }^{25}$ Combining that with the $21 \%$ reduction in ETS sectors is expected to accomplish the overall emissions reduction goal of $20 \%$ in 2020 vs. 1990 levels. ${ }^{26}$

Therefore, as with ETS Phases I and II, emission reduction efforts for non-ETS sectors allocate responsibility based on each Member States' relative income. Wealthy countries must cut emissions, while poorer countries may increase emissions. However, this approach is built upon the assumption that less wealthy countries will experience a higher rate of economic growth, leading to higher emissions, so such countries will still effectively need to reduce their emissions over the period. ${ }^{27}$ Nevertheless, in striking the Effort Sharing Decision, Member States divided up emission reductions based on relative wealth.

\section{Current Schemes Unsuccessful}

While the current allocation schemes described supra have certainly done something to reduce GHG emissions, they have been demonstrably inadequate. By almost every account, the Kyoto Protocol has not resulted in substantial emissions reductions. It has not obtained the formal agreement of the United States, and formal signatories appear to be largely unmoved by it with respect to actual energy policy decisions. Emissions continue to rise, and when and where they stall, economic slowdowns appear to account for that phenomenon as much or more than Kyoto-inspired policy. By all accounts, the first phase of the EU ETS did not produce emissions reductions that otherwise would not have occurred. It is possible that the current phase will fare much better. But the current phase requires centralized planning and regulation in the form of per-facility targets that is hard to imagine outside of federal or quasi-federal union, and thus is hard to imagine working as part of an international agreement on the scale of Kyoto or even a multilateral agreement among non-common-union nation states.

The Kyoto and to a large Extent EU approach to allocation is costinsensitive. Emission reductions targets are allocated without regard to the question of how much it would cost to have each target achieved. Thus, on its face, putting aside the possibility that trading or other mechanisms will help equalize costs to a degree, this approach calls on some actors to take on targets that entail very high compliance costs relative top others.

25. Questions and Answers on the Effort Sharing Decision (October 2013), supra note 19.

26. Effort Sharing Decision, EUROPEAN COMM'N, supra note 21.

27. Id. 
From both an efficiency and equity perspective, this is problematic, as commentators have explained. ${ }^{28}$

The post-Kyoto round of talks have focused on inclusion of a larger number of nations, including poorer or less industrialized nations, and have involved extensive discussions of differentiated responsibilities based on a range of factors - wealth or GDP of the nation, economic dependence on fossil fuel production, threat from climate change and need to adapt, as, for example, in the case of low-lying countries. But the compliance costs for each nation of emission reductions - and in particular costs of switching from coal to oil to natural gas and from fossil fuels to renewables-has not been an explicit focus of the largely unfocused discussions of differentiated responsibilities.

\section{Proposed And Possible Future Allocation Regimes}

\section{A. Equal Emissions Per Capita, Emissions Based on Historical Contribution to Climate Change, and Emissions Based on GNP or GNP Per Capita}

Given the failure of the current regime, it is natural to ask whether a different emissions reduction scheme would do better. There has been no shortage of other schemes proposed. For example, some developing nations such as China have proposed allocating emissions reductions per capita. ${ }^{29}$ The aim of such a scheme would be to allow roughly equal emissions for each person in the world, regardless of where they lived. "The intuition here is that every person on the planet should begin with the same emissions right; it should not matter whether people find themselves in a nation whose existing emissions rates are low or high.”30 While such a scheme certainly has intuitive appeal, there are several reasons why it will likely never become the basis for a new agreement. First, for

28. Robert N. Stavins, A Meaningful Cap-and-Trade System to Address Climate Change, 32 HARV. ENVTL. L. REV. 293, 294 (2008) ("Many analysts - particularly economists - have been highly critical of the Kyoto Protocol, noting that, because of specific deficiencies, it will be ineffective and relatively costly for the little it accomplishes.") (citing Joseph E. Aldy, Scott Barrett \& Robert N. Stavins, Thirteen Plus One: A Comparison of Global Climate Policy Architectures, 3 Climate PoL’y 373 (2003)).

29. See, e.g., China's National Climate Change Programme (promulgated by the Nat'l Development and Reform Commission, June 2007), at 58 (China), www.ccchina.gov.cn/ website/ccchina/upfile/file188.pdf.

30. Eric Posner \& Cass Sunstein, Should Greenhouse Gas Permits Be Allocated on a Per Capita Basis?, 97 CaLIF. L. Rev. 51, 53 (2009). 
pragmatic reasons, developed countries like the United States will likely never agree to it. "Nations are unlikely to sign an international agreement if they will be significant net losers, and wealthy nations might lose a great deal from any approach that does not use existing emissions as the baseline for reductions." 31 Second, it is not even clear that the per capita approach would benefit most developing nations. As Posner and Sunstein demonstrate, "there are rich small states [], and poor big states [], and everything in between. $[T]$ here is no statistically significant correlation between population and per capita GDP.”32 While China and India would certainly benefit from such a scheme, many other developing nations would not.

In sum, it is highly unlikely that a per capita emissions scheme will form the basis of a new agreement going forward, and it is equally unlikely that such a scheme would fulfill the distributive justice rationales that underpin it in any event.

Similar objections surround proposals to gear emissions reductions to nation's historical contributions to net carbon emissions. In this polluterpay approach, nations that have long been industrialized would pay much more than newly or non-industrialized nations. But, normatively, holding current populations of industrialized countries responsible for past emissions by past generations is problematic, at least from some philosophical perspectives as Posner and Sunstein also argue. Moreover, politically, the idea that past polluting nations owe much more in terms of emissions reduction efforts because of their past "wrongs" would seem to be a political non-starter that would run counter to the "we are all in this together" spirit of collective action against climate change, which may be necessary to achieve success.

Allocations tied to a nation's GDP are also normatively problematic, because there is no widespread acceptance by as to what constitutes a "rich" country as opposed to a "middle class" or poor one and, even more so, there is no widespread agreement as to how much of a social obligation or an obligation of helping rich nations owe or should be deemed to owe poor ones. Indeed, it is not obvious that there is a general buy-in to the idea that rich countries should substantially aid poor ones: much foreign aid by wealthy countries, and by the U.S. in particular, appears driven by military and geopolitical considerations more than a normative commitment to help nations in need.

31. Id. at 55.

32. Id. at 74. They also note that because permits are allocated to governments, not citizens, wealthy elites in developing nations would likely still hold the dominant number of permits. Id. at 75 . 


\section{B. Allocation Based on Net Welfare Benefits of Emissions Reductions and Climate Change Mitigation}

As economists have pointed out, the equal-percentage-reduction approach of Kyoto and (to a lesser degree) the EU has no rationale in welfare economics, which would endeavor to factor in costs and benefits to each nation of reducing emissions. But an allocation regime based on equalwelfare-effects would be far too complex and contestable to be workable. How much each nation benefits from reducing carbon in the atmosphere is not an easy question: some nations are more vulnerable to climate change but there is a great deal of uncertainty regarding vulnerabilities in the event of different climate change scenarios, as well as the basic uncertainty as to what effect any climate change mitigation effort will have on climate change. Reducing emissions may have substantial non-climate health benefits, such as less asthma or other lung diseases, but these too may be contestable and it is not obvious that a nation that has not been motivated to achieve these health benefits for their own sake would accept their being used as a rationale for being subject to a higher emissions reductions target than they would have received without consideration of those benefits.

In welfare economics, benefits are only half the picture; costs are the other half. To assess the full economic costs to each nation of emissions reductions, an assessment, not just of the direct cost of compliance with possible emissions reduction targets, but also with the overall economic effects of the compliance efforts, including downstream effects on investment, savings, and employment would be required. As suggested by the debates in the United States over whether any given environmental regulation will ruin an industry or actually help it long-term, or whether an environmental regulation is an economic drag or a long-term win-win, it is highly contestable what the overall economic costs of a nation shifting to a low-carbon or no-carbon future will be. For that reason presumably, and defensibly, the EPA in the Regulatory Impact Analysis for the Clean Air Act refuses to attempt to quantify social costs of its rule and uses compliance costs as the sole costs to be considered as part of a cost benefit analysis. As discussed below, however, the direct, upfront, compliance costs - the costs of switching from coal to natural gas and/or coal and gas and oil to renewables-may be more subject to reliable, commonly-accepted estimates. 


\section{Other Possible Schemes}

There are many other possible bases for allocating emissions. ${ }^{33}$ Yet so far, none of them has gained any traction in the international talks designed to lead to a new agreement. Instead, the latest U.N. Framework Convention on Climate Change (UNFCCC) Conference of the Parties (COP21) has relied on Intended Nationally Determined Contributions (INDCs), a process whereby nations determine their own contributions to GHG emissions reductions. The hope is that such an approach "can create a constructive feedback loop between national and international decision-making on climate change." ${ }^{34}$ However, such INDCs have also been criticized as lacking transparency. ${ }^{35}$ In addition, while almost $87 \%$ of global emissions are covered by countries that have submitted INDCs, ${ }^{36}$ there are serious concerns that these pledges, even if adhered to, will not meet the goal of keeping average global temperatures below 2 degrees Celsius. ${ }^{37}$

Thus, a reasonable question is: are there better ways to allocate responsibility for carbon emissions (and net reduction thereof) among nations? Is there an allocative approach that has not yet been tried, but that may work better in terms of getting nations to agree and keeping average global temperatures below 2 degrees Celsius?

\section{A Cost-Sensitive ApPROACH}

Nearly every criticism of emissions reduction measures includes a concern over costs. Nations are concerned that the overall costs of GHG reductions will be too high, and/or that such costs will not be shared equitably among nations. One response to such criticism, then, would be to make costs an explicit part of any emissions reduction scheme.

33. See Daniel Bodanski et al., Pew Center on Global Climate Change, INTERNATIONAL ClimATE EFFORTS BEYOND 2012: A SURVEY OF APPROACHES 1 (2004).

34. See What is an INDC?, WORLD RESOURCES INSTITUTE (2015), http://www.wri.org/ indc-definition.

35. See Thomas Damassa et al., Interpreting INDCs: Assessing Transparency of Pos-2020 Greenhouse Gas Emissions Targets For 8 Top-Emitting Economies, WoRLD RESOURCES INSTITUTE, at 7 (Dec. 2015), http://www.wri.org/sites/default/files/wri_wp_ interpretingINDCs.pdf.

36. See U.N. Secretariat, Synthesis Report on the Aggregate Effect of the Intended Nationally Determined Contributions, at 4, U.N. Doc. FCCC/CP/2015/7 (Oct. 30 2015), http://unfccc.int/resource/docs/2015/cop21/eng/07.pdf.

37. See Int'l Energy Agency, Energy and Climate Change, at 12 (2015), http:// www.iea.org/publications/freepublications/publication/WEO2015SpecialReportonEnergy andClimateChange.pdf; but see David Victor \& Charles Kennel, Climate Policy: Ditch the 2 Degree C Warming Goal, Nature Publishing Group (Oct. 1, 2015), http://www. nature.com/news/climate-policy-ditch-the-2-c-warming-goal-1.16018, for a criticism of the 2 degree target. 
In this section, we examine two different models for a cost-sensitive emissions reduction approach. Both models derive from prior EPA rulemakings under the Clean Air Act. The first and more traditional model seeks to equalize costs among states with respect to each ton of emissions reduction. In other words, under this model, states subject to the rule must each reduce emissions in the amount that can be achieved at a certain price-per-ton of abatement. This was the EPA's approach under its various ozone abatement rules, most recently the Cross State Air Pollution Rule, or CSAPR, as discussed more fully below.

The second cost-sensitive approach is the one the EPA employed in its Clean Power Plan. Under this approach, the EPA did not explicitly seek to equalize the cost-per-ton of emissions abatement. Instead, the EPA seems to have made certain assumptions about how much it would cost states to switch to clean power sources, based on factors such as the state's natural endowments (sunshine, wind, etc.), the amount of clean power capacity already built or planned, a state's political capacity to make further emissions reductions, and grid accessibility for that state. These various "cost” measures then became factors in the amount of GHG reductions each state would be required to bear. The costs were not equalized on a "per ton" measure, but rather in a more amorphous, overall way.

\section{A. The Traditional Cost-Conscious Model}

The EPA initially designed an emissions reduction system that tries to roughly equalize costs among polluters when it promulgated rules regarding ozone precursors. In the EPA's 1998 nitrogen oxide (NOx) SIP call, the EPA decided that the 23 "significant contributor" upwind states "need only reduce their ozone by the amount achievable with "highly cost-effective controls," " which the EPA defined to be "ones that could be achieved (in the EPA's estimate) for less than $\$ 2000$ a ton." ${ }^{38}$ The result of this costbased cutback meant, of course, that emissions reductions "would vary from state to state depending on variations in cutback costs." 39 However, the costs per ton of abatement would remain roughly the same. In other words, each state would be required to reduce NOx emissions by the amount that could be achieved at a uniform cost, but because the costsper-ton of reduction for some states would be higher (generally those were

38. See Michigan v. EPA, 213 F.3d 663, 6675 (D.C. Cir. 2000).

39. Id. 
the states that had already taken the easy measures to reduce emissions) and costs-per-ton of reduction for some states would be lower (generally those were the states that hadn't done much yet, and thus had several easy measures still available to them), the end result was that states faced different percentages of required reduction depending on where they were along the marginal abatement cost curve.

A similar design was carried forward into EPA's Cross State Air Pollution Rule, or CSAPR. Here, EPA designed a system with respect to the ozone precursors nitrogen oxide (NOx) and sulfur dioxide $\left(\mathrm{SO}_{2}\right)$. If an "upwind" state emits these chemicals in threshold amounts detected at "downwind" states, then the CSAPR mandates that the upwind states reduce emissions by reference to certain cost thresholds, which would be uniformly applied within groups of upwind states. These uniform or equal cost thresholds are then applied to create different emissions "budgets" in each upwind state. As the Supreme Court described it: "EPA translated the cost thresholds it had selected into amounts of emissions upwind States would be required to eliminate. For each regulated upwind State, EPA created an annual emissions 'budget.' These budgets represented the quantity of pollution an upwind State would produce in a given year if its in-state sources implemented all pollution controls available at the chosen cost thresholds." 40

As with the NOx SIP call, each upwind state under the CSAPR is subject to a uniform cost threshold, ${ }^{41}$ but these uniform costs translate into different emissions "budgets" for each upwind state. ${ }^{42}$ EPA calculated how much pollution each upwind State could eliminate "if all of its sources applied pollution control technologies available at particular cost thresholds," 43 and then required the states to reduce pollution by that amount. Again, this approach attempts to roughly equalize the costs per ton of reduction that the upwind states will face. Indeed, EPA explicitly rejected a uniform percentage-of-emissions reduction rule (akin to the Kyoto rule discussed

40. EPA v. EME Homer City Generation, L.P., 134 S. Ct. 1584, 1621-22 (2014).

41. Technically, the cost thresholds were uniform within different groups of upwind states. EME Homer City Generation, L.P., v. EPA, 795 F.3d 118, 126 (D.C. Cir. 2015) ("In the end, EPA adopted four cost thresholds for the 27 upwind States subject to the Transport Rule. For all States subject to the Rule for annual NOx, EPA set a \$500/ton cost threshold. See Transport Rule, 76 Fed. Reg. at 48,250. For States subject to the Rule for ozone-season NOx, EPA also set a \$500/ton cost threshold. See id. For States subject to the Rule for SO2, EPA divided the States into two groups. For Group 1 States, EPA set a $\$ 2,300 /$ ton cost threshold. See id. at 48,259. For Group 2 States, EPA set a \$500/ton cost threshold. See id.”).

42. See, e.g., Final June Revisions Rule State Budgets and New Unit Set-Asides TSD, U.S. EnVtL. Prot. AgEncy Off. OF Air \& RADiation (June 2012), http://www3.epa. gov/crossstaterule/pdfs/FinalJuneRevisionsRuleStateBudgetsandNewUnitSetAsidesTSD. pdf (widely varying state budgets).

43. EME Homer City Generation, L.P. v. EPA, 795 F.3d 118 (D.C. Cir. 2015). 
supra) because such a rule would have had perverse effects. As the EPA noted in one of its Technical Support Documents for the Transport Rule: "since all contributing states would be required to do the same percent reduction of existing emissions, states that had previously implemented stringent control programs might not be able to achieve the required reductions using existing control technologies, while others that had previously done little (and presumably have larger absolute contributions) would achieve their required reductions using significantly less than optimal control technologies." 44

Of course, some of EPA's hesitation to use equal percentage reduction of emission measures in the CSAPR (and in its NOx SIP call) was driven by the complexity of NOX and SO2 interactions, and the impossibility of tying individual upwind states' contributions to particular downwind states' receptors. ${ }^{45}$ Nonetheless, the equal costs idea played a prominent role in the design of the CSAPR.

This roughly equal costs measure then resulted in varying emissions budgets for each state. EPA assumed a traditional increasing marginal cost curve. As it stated in one of its technical documents to the Transport Rule (the precursor to the CSAPR), "EPA designed a series of IPM [Integrated Planning Model] runs that imposed increasing marginal costs for reduction of SO2, annual NOx, or ozone season NOx emissions and tabulated those projected emissions at each cost level."46 In other words, EPA assumed the marginal cost of emissions abatement would increase as that abatement increased. With that assumption in mind, EPA then selected various points along this increasing marginal abatement cost curve and projected emissions at those levels. It used air quality measures to determine where the marginal benefits of increased abatement would decrease. Based on these data, EPA decided what each upwind state's emissions budget would be.

44. Alternative Significant Contribution Approaches Evaluated, U.S. ENVTL. Prot. AgENCY OfF. OF Air \& RADiATION (July 2000), http://perma.cc/4LJC-SY9N.

45. See EPA v. EME Homer City Generation, L.P., 134 S. Ct. 1584, 1604-05 (2014). Note that these concerns should not play as large a role with respect to GHG emissions, because those emissions do not depend on interactions with other GHG emissions for their potency, nor do they cause local effects that depend on exactly where the wind blows them.

46. See Analysis to Quantify Significant Contribution, U.S. ENVTL. PROT. AgENCY OFF. OF AIR \& RADIATION (JULY 2000), at 6, http://www3.epa.gov/crossstaterule/pdfs/TSD_ analysis_to_quantify_significant_contribution_7-8-10.pdf. 


\section{B. EPA's Clean Power Plan Considers Costs Differently}

The EPA's Clean Power Plan, on the other hand, is sensitive to costs in a much different way, perhaps because it addresses power plants' carbon dioxide emissions, ${ }^{47}$ and is aimed, in addition to enhancing efficiency, at switching power generation away from carbon emitting sources altogether. ${ }^{48}$ Under the Clean Power Plan, the EPA assigned emission reduction targets to each state. ${ }^{49}$ These targets vary in terms of the requisite emission reductions, and are not equal in terms of either a required percentage reduction in net emissions or emissions per capita, or emissions per household. ${ }^{50}$

More precisely, under the EPA's plan, each state must meet a target of emission reduction, called the Best System of Emission Reduction, or BSER. This derives from Section 111(d) of the Clean Air Act's requirement that EPA prescribe regulations that require each state to submit a plan that "establishes standards of performance" for existing sources of air pollution. A "standard of performance" is in turn a term of art, defined under Clean Air Act Section 111(a)(1) to mean "a standard for emissions of air pollutants which reflects the degree of emission limitation achievable through the application of the best system of emission reduction which (taking into account the cost of achieving such reduction and any non-air quality health and environmental impact and energy requirements) the Administrator determines has been adequately demonstrated.”

Based on its evaluation of various GHG abatement measures, "EPA identified four categories of demonstrated measures, or 'building blocks,' that are technically viable and broadly applicable, and can provide costeffective reductions in $\mathrm{CO}_{2}$ emissions from individual existing EGUs."51 These building blocks include the three that were reflected in the final rule: (1) Increasing the operational efficiency of existing coal-fired power plants; (2) Shifting electricity generation from higher emitting fossil fuelfired steam power plants (generally coal-fired) to lower emitting natural

47. See FACT SHEET: Clean Power Plan Overview, U.S. ENVTL. Prot. AgenCy, at http://www2.epa.gov/cleanpowerplan/fact-sheet-clean-power-plan-overview (last updated Apr. 11, 2016).

48. See FACT SHEET: Clean Power Plan Benefits of a Cleaner, More Efficient Power Sector, U.S. EnVTL. Prot. Agency, http://www2.epa.gov/cleanpowerplan/factsheet-clean-power-plan-benefits-cleaner-more-efficient-power-sector (last updated Aug. 13, 2015).

49. See FACT SHEET: Clean Power Plan Framework, U.S. ENVTL. Prot. AgENCY, http://www2.epa.gov/cleanpowerplan/fact-sheet-clean-power-plan-framework (last updated May 11, 2013).

50. See id.

51. U.S. Envtl. Prot. Agency Off. of Air \& Radiation, GHG Abatement MEASURES 1-1 (2014), http://www2.epa.gov/sites/production/files/201406/documents/2014 0602tsd-ghg-abatement-measures.pdf. 
gas-fired power plants; and (3) Increasing electricity generation from renewable sources of energy like wind and solar. ${ }^{52}$

The EPA applies these "building blocks" in order to calculate the BSER for each state. 53 EPA's exact formula is complex, and involves a consideration of a number of judgment calls. In its Goal Computation Technical Support Document, EPA used historical 2012 emissions data for each state as the basis for each state's emission rate goal under the Proposed Rule. ${ }^{54}$ EPA then applied the BSER "building blocks" to compute interim and final goals in various ways. In doing so, certain cost-based factors became clear.

For Building Block 1, for example-the operational efficiency of coal plants-EPA assumed that, to a certain extent, heat rate improvements at coal plants (i.e., improvements in the amount of energy required to produce each kWh of energy) would be highly economically beneficial, perhaps even paying for themselves. ${ }^{55}$ EPA looked at factors such as the best historical heat rate performance for each EGU and calculated the overall potential for heat rate improvements within each of 3 regional grid interconnections. ${ }^{56}$ These factors are consistent with a traditional model where we assume steadily rising marginal costs of abatement. Indeed, EPA studied various low-cost measures such as equipment upgrades and contrasted them with higher-cost "best practices" and noted that some EGUs could achieve almost all of their emission reductions using equipment upgrades alone. ${ }^{57}$

When it comes to energy efficiency in consumption or demand-side efficiency, which EPA left out of the final "building blocks" (though it still gives states the opportunity to get credits toward its emission targets for certain types of energy efficiency projects), EPA also assumed a

52. See U.S. Envtl. Prot. Agency, Clean Power Plan-Technical Summary FOR STATES 1, http://www3.epa.gov/airquality/cpptoolbox/technical-summary-for-states.pdf (last visited Feb. 15, 2016).

53. Id. at $1-2$.

54. See U.S. EnVtl. Prot. Agency Off. of Air \& Radiation, Goal Computation TECHNICAL SUPPORT DOCUMENT 4, 8 (2014), http://www2.epa.gov/sites/production/files/201406/documents/20140602t sd-goal-computation.pdf.

55. See U.S. EnVtl. Prot. Agency OfF. OF Air \& Radiation, Greenhouse Gas Mitigation Measures 2-65 (2015), http://www.epa.gov/sites/production/files/201511 / documents/tsd-cpp-ghg-mitigation-measures.pdf.

56. Id. at 2-22. See also U.S. EnVtl. Prot. Agency OfF. Of Air \& Radiation, $\mathrm{CO}_{2}$ Emission Performance Rate And Goal Computation Technical Support DoCumENT For CPP FInAl Rule 3 (2015), http://www.epa.gov/sites/production/files/ 2015-11/documents/tsd-cpp-emission-performance-rate-goal-computation.pdf.

57. See U.S. Envtl. Prot. Agency Off. of Air \& Radiation, supra note 55, at 2-63. 
traditional rising marginal cost of emissions abatement curve. EPA expressly noted that: "It is generally assumed in most energy efficiency projections that the cost of installing energy efficiency measures will become more expensive into the future as state programs move beyond 'low-hanging fruit' and increasingly focus on achieving deeper and broader energy savings through whole-building, multi-fuel programs addressing new buildings and building retrofits." 58

On the other hand, when applying the renewable energy building block, EPA appears to have assumed a very different cost curve. In the proposed rule, EPA looked at the "current goals of leading states in the same region," which reflected "renewable potential in particular regions of the country." 59 EPA used "the state-level effective RE levels derived from RPS requirements to quantify regional RE targets consistent with states' reasonable level of increased RE development."60 EPA derived regional RE generation targets and growth rates and imposed "the same regional RE target in percentage (share of total generation) terms to all states in a given region." 61 The regional targets would be set for the year 2029. "The EPA then determined the constant rate at which each region would need to increase its generation each year to reach the regional RPS target, if these rates are applied in the period 2017-2029. The constant rate of annual RE generation increase calculated from this approach is called the growth factor." 62 Regional growth factors varied from a low of $6 \%$ in the West region to a high of $17 \%$ in the East Central region. ${ }^{63}$

Implicit in the constant growth factor is that EPA either assumed a flat marginal cost curve, or was simply indifferent to costs. What EPA did not do was assume a rising marginal cost curve and assume that early growth would be more rapid or that states that hadn't done much already could do more at lower cost. Indeed, EPA seemed to make the opposite assumption in some cases, due to the design of the regional targets, as discussed infra.

Importantly, "the regional RE target is not applied directly as an immediate requirement of each state, but is instead used to calculate a regional growth factor that is then applied to each state's pre-existing RE

58. U.S. Envtl. Prot. Agency Off. of Air \& Radiation, Projecting EGU CO2 EMISSION PERFORMANCE IN STATE PlANS 27 (2014), http://www2.epa.gov/sites/production/ files/2014-06/documents/20140602tsd-projecting-egu-co2emission-performance.pdf.

59. See U.S. Envtl. Prot. Agency OfF. Of Air \& Radiation, supra note 51.

60. Id. at $4-12$.

61. Id. at $4-19$.

62. Id. at $4-19$.

63. Id. at 4-18. The West region is comprised of Colorado, New Mexico, Wyoming, Montana, and all states to the west (except Alaska and Hawaii). The East Central region is comprised of Ohio, West Virginia, Virginia, Maryland, Delaware, Pennsylvania, and New Jersey. See id. at 4-14. 
generation, such that historic RE performance acts as a limiting factor on the extent to which a state is assumed to reach the regional target." ${ }^{64}$ What this meant was that "the absolute megawatt-hour target will be smaller for states starting with a lower absolute amount of RE generation and larger for a state starting with a higher absolute amount of RE generation." ${ }^{65}$ Moreover, "several states do not reach the RE percentage target in the proposed approach, such as Kentucky in the Southeast and Nevada in the West." 66 Kentucky, which got $0 \%$ of its energy from renewables in 2012, would only get to $1.9 \%$ by 2029 , whereas Nevada, which was at $8 \%$ in 2012, would get up to $19 \% .{ }^{67}$ By contrast, Ohio, which got only $1 \%$ of its energy from renewables in 2012, would get to $10.6 \%$ by 2029 , and Oregon, which got $12 \%$ of its energy from renewables in 2012, would get all the way up to $20.6 \%$ by 2029.68

These vast discrepancies are due to several regional and state-specific factors, but EPA was clear that its overall approach was "designed to respect each state's ability to improve toward the RE targets."69 Again, EPA did not simply assume that all states faced a roughly similar (and rising) marginal cost curve. Instead, EPA was sensitive to the various factors-such as regional differences and natural endowments - that might limit states' ability to "switch" power generation to renewables. While the CPP's final rule is still more complex-it both changes the final state targets and the methods by which states can meet those targets ${ }^{70}$ - there is still no assumption that states that have not deployed much RE can rely on "lowhanging fruit" to do more than states that have. ${ }^{71}$

Indeed, the CPP has come under criticism from some states and commentators for precisely this reason. States have complained that the

64. Id. at 4-19 (emphases added).

65. Id.

66. Id.

67. Id. at $4-24$.

68. Id.

69. Id. at 4-20 (emphasis added).

70. See Are you better off under the Clean Power Plan than you were 14 months ago?, INT'L DisT. ENERGY Ass’N (Aug. 12, 2015), http://www.districtenergy.org/blog/ 2015/08/12/are-you-better-off-under-the-clean-power-plan-than-you-were-14-months-ago/.

71. On the other hand, some states with already robust $\mathrm{RE}$ are given relaxed targets because each state is subject to the same RE growth assumption until it reaches the RE generation target, whereupon it is kept at that target level for the remainder of the relevant time period. See U.S. EnVTL. Prot. Agency OfF. OF Air \& RADiATION, GHG AbATEMENT MEASURES 4-19 (2014), http://www.epa.gov/sites/production/files/2014-06/documents/ 20140602tsd-ghg-abatement-measures.pdf. 
CPP demands something of all states, and does not systematically "reward" states that have already done more to switch to renewables, nor "punish" states that have not. ${ }^{72}$ Rather than being a flaw, this appears to be part of the overall design.

\section{A "Switching Costs" Approach}

The above analysis of the Clean Power Plan and the CSAPR is consistent with the notion that where a regulatory regime is focused not simply on increasing efficiency, but on "switching" generation from one form to another, we should assume a very different marginal cost of abatement function and not simply demand more from states that have not yet done much "switching." In other words, the goal of the Clean Power Plan was not simply to make current coal plants more efficient (i.e., building block \#1), but rather to replace some of those plants with low or no-GHGemitting renewables. In setting the regional targets to support its RE building block, EPA was sensitive to natural endowments, such as sunshine or wind, in order to set the assumed renewables growth rates for states within that region. These natural endowments certainly affect the switching costs for Building Block 3 faced by the states. There are also, of course, significant capital costs involved in building out renewable capacity, whether it be for wind or solar or other forms of renewable energy. Such capital costs are particularly high for utility-scale thermal solar projects and offshore wind projects. ${ }^{73}$ Indeed, capital costs may be a reason to assume, in a "switching" scenario, a marginal cost of abatement function that is not the traditional steadily rising one, but rather one that has a significant "hump"

72. See Press Release, Dep’t of Envtl. Prot., Christie Admin. Seeks Admin. Stay and Reconsideration of EPA's Clean Power Plan (Sept. 2, 2015), http://www.nj.gov/ dep/newsrel/2015/150073.htm (quoting DEP Commissioner Bob Martin, "One of the greatest ironies of the so-called Clean Power Plan is that while New Jersey has made great strides in reducing carbon emissions and other pollutants as well that cause smog and other air quality problems, states that are upwind of New Jersey actually are assigned emission reduction goals that fall far short of what New Jersey has already achieved.”); see also William W. Buzbee et al., Ctr. For Progressive Reform, The Clean POWER Plan: Issues To WATCH 62-63 (1506 ed. 2015), http://progressivereform.org/ articles/CPP_1506.pdf (“This 'every state must do its part' approach arguably results in failing to reward states that made significant investments in de-carbonizing measures in the past while rewarding those states that put off such investments," while warning that generalizations are "tricky" and that compliance cost estimates across states vary widely").

73. See U.S. ENERGY INFO. ADMIN., UPDATED CAPITAL COST ESTIMATES FOR UTILITY SCALE ElECTRICITY GENERATING Plants 6 (2013), available at http://www.eia.gov/fore casts/capitalcost/pdf/updated_capcost.pdf. 
around the time when new facilities must be constructed. ${ }^{74}$ This is especially true when switching to renewables as opposed to natural gas. ${ }^{75}$

\section{Applying a Cost Sensitive Model to the INTERNATI NAL CONTEXT}

The state-specific targets in EPA's proposed Clean Power Plan received much criticism from individual states on technical grounds, and the final rule no doubt will be subject to technical criticisms. But for our purposes, the key question is not whether EPA got its formula right or applied it correctly in each instance. The question is whether the idea implicit in EPA's approach - that the different costs each state faces in terms of switching to lower-carbon or no-carbon generation-should factor into an allocation of emissions reductions. EPA's plan raises the question of whether compliance costs - as opposed to the more amorphous and difficult-to-assess economic costs - should count in a substantial way when responsibilities for a common pollution problem (here, climate change) are allocated among states.

The first thing to note is that we assume the cost function for GHG reductions in the international context will follow the more complex "switching costs" function described supra instead of the traditional steadily increasing function of the CSAPR. By "costs" we focus, as EPA does under the Clean Power Plan, largely on switching costs-i.e., the costs of switching from coal to gas, and gas to solar and/or wind. No doubt there will be some high-emitting nations for which relatively low-cost efficiency measures can do a great deal to reduce GHG emissions. But ultimately we assume that such measures will be of limited value and that, ultimately,

74. There is also some reason to believe that the marginal cost of emissions abatement would decrease after the capital expenditure "hump" as states (and nations) gain experience in the new technologies. For example, Germany has lower installed costs of solar than the United States, in part because its solar sector is more robust. See FrED HeUTTE, Nw. ENERGY COAL., EXPERIENCE CURVES AND SOLAR PV (2015), available at http://www.nwcouncil.org/ media/6867808/2012-09-03-nwec-experience-curves-and-solar-pv.pdf.

75. EPA separately analyzed the costs of switching from coal to natural gas (Building Block 2). There it found that the cost of fuel, and not capital costs, were the major cost drivers. See U.S. Envtl. Prot. Agency OfF. Of Air \& RAdiation, supra note 71 , at $6-5$. 
those nations will face a "hump" in their cost curves as they are forced to switch their forms of power generation. ${ }^{76}$

Therefore, using the Clean Power Plan's cost assumptions as a starting point, we ask the question: could a "switching costs" approach form a plausible basis for an international agreement? In other words, could an approach that is sensitive to different nations' costs (whether capital costs or natural endowments) and different regional factors, resulting in potentially quite varied emissions reduction goals, succeed where other approaches have failed?

\section{A. The Advantages of a Cost-Sensitive Approach}

\section{Facilitating Agreement}

An approach of imposing relatively lower percentage reductions on states or nations with relatively high switching costs could be helpful in obtaining agreement among states or nations even if some sort of trading regime is also part of the proposed regime. For a nation or state facing high switching costs, the availability and costs of any emissions credits that could be bought under a trading regime will, ex ante, be quite unpredictable. Thus, in deciding whether to agree or how strongly to oppose a proposed emission reductions target, the powers-that-be in the nation or state with high switching costs will have to assume that they may be called upon to make all the emissions reductions through actual reduction within their own borders as opposed to relying on the possibility that lower cost emissions credits will be available to be purchased from states or nations that face relatively lower switching costs.

To make this point more concrete, imagine a regime with just two states or nations-A and B. A has relatively high switching costs, because it has four large coal-powered plants, no natural gas infrastructure yet, and only modest but expandable wind power infrastructure that provides a small fraction of its power. B has one old coal-powered plant, two natural gas plants with expansion capacity and substantial wind, solar and hydropower

76. For simplicity's sake, we focus here on power generation, because it is the single largest sector responsible for GHG emissions globally. See THOMAS BRUCKNER ET AL., INTERgOVERNMENTAL PANEL ON ClimATE CHANGE, WORKING GROUP III FIFTH AsSESSMENT REP. 516 (2014), available at file:///Users/erinmuniga/Downloads/ipcc_wg3_ar5_ chapter7\%20(1).pdf. (noting that "[t] he energy supply sector is the largest contributor to global greenhouse gas emissions" and that "[i]n 2010, the energy supply sector was responsible for approximately 35\% of total anthropogenic GHG emissions"). Nonetheless, we recognize that GHG emission sources come from many different sectors, and power generation is only one piece of the puzzle. We also recognize that a "switching costs" approach may be of limited value for countries that currently have very little in the way of GHG emissions, but might have such emissions in the future. 
infrastructure, with possibilities for expanded use. In a Kyoto-like regime, both A and B might be told that they must reduce emissions by $50 \%$. To do so, A could close two of its four coal-powered plants, while developing natural gas generation capacity and ramping up renewable capacity. The costs of doing so would be high. State B would have to do quite a bit less to meet its target, as it already has natural gas power generation and renewable generation that could be ramped up to substitute for the power currently generated by its single coal power plant (which, let us assume, now accounts for a large share of its emissions). State B could exceed its $50 \%$ target by relying more on renewable expansion than natural gas expansion, and it could then sell excess emissions credits to State A. But State B might decide not to over-comply, that is, exceed the $50 \%$ target, because of questions about the reliability of renewables. Moreover, if State B did over-comply and exceed the $50 \%$ target, it might not want to sell credits corresponding to any extra emissions reductions to State A at all. Rather, State A might prefer to bank those credits as protection in case it needs to emit more from its natural gas plants because of unanticipated surges in power demands or because of problems of reliability in the power produced by its renewables infrastructure. Indeed, under the S02 trading regime established by the 1990 Clean Air Act amendments, utilities engaged in such banking, with the result that there was less selling by "overcomplying" utilities than might have otherwise been the case. Finally, ex ante, State A would have no way of knowing the price of any credits that would be sold by State B. The overall point is simply this: even where a trading regime might help defray cost faced by states or nations that must transition to cleaner energy ex post (after the targets are accepted by the states or nations), ex ante, making targets sensitive to switching costs might facilitate the agreement to targets by states or nations that face relatively high switching costs.

\section{Resonating with a Message of Unity}

Second, being sensitive to switching costs treats climate change as a wholly collective problem created by all, and for which all must make roughly "equal” contributions in terms of increased electricity rates, at least. By contrast, in approaches where allocation are based on percentage reductions in a state's emissions or emissions per capita, the costs any person incurs may depend largely on his or her State of current residence. To make current residency a key factor in the burdens individuals bear might be tenable if we assume that the current residents of a state or nation are responsible in 
some meaningful sense for the aggregate or per capita emissions levels in that state or nation. But where there is substantial mobility across state or national lines, and/or where emissions levels in each state or nation are in any case a result of historical choices made over several generations, this assumption seems untenable. Thus, the switching cost approach has a cosmopolitan, beyond-boundaries, all-in-it-together appeal that regimes based on equal emissions reduction percentages do not.

The switching costs approach also avoids imposing different burdens on relatively wealthier states as compared to less wealthy ones - at least state GDP or per capita GDP is not an explicit criterion. By avoiding State GDP as a factor, the switching costs approach avoids the normatively intractable debates about whether there should be distributive justicebased redistribution from wealthy states to poor ones and how much richer countries owe poorer ones and what counts as a rich or poor state. ${ }^{77}$ In the U.S. context, where there is a governance structure that allows for redistribution from wealthy to poor regardless of State residence, as for example, in the form of all subsidies for low-income households, EPA can avoid distributive justice-based calls for greater costs to be borne by wealthy states without simply ignoring distributive justice altogether.

\section{B. Do the Advantages Apply Outside the U.S.?}

These advantages of the switching costs approach may or may not translate onto the international scale, where we are speaking of a group of nations rather than a group of states that are part of a federal regime with federal constitutional supremacy. The we-are-all-in-it-together appeal of the EPA approach, as well as its implicit reliance on direct aid to individuals as a means of addressing distributive justice, might work less well in the EU context than in the U.S. context because of the greater sense of distinct national identity and legal sovereignty EU member states have vis-à-vis the EU, as compared to U.S. states vis-à-vis the U.S. government. The normative appeal of the EPA approach might be even less robust in the context of a multilateral agreement involving countries throughout the planet.

However, the switching costs approach may help facilitate agreement on the international level, just as it is intended to foster political consensus domestically within the United States. The "break" given nations that face large switching costs may make them less hesitant to enter into an

77. See, e.g., Lisa Friedman \& Gayathri Vaidyanathan, All eyes on India in the wake of U.S.-China agreement, E\&E REP. (Sept. 25, 2015), http://www.eenews.net/eenewspm/ 2015/09/25/stories/1060025351 (noting that India’s Prime Minister Modi’s speech at the United Nations focused on what he termed "climate justice"). 
agreement. Moreover, under this approach, more is asked of nations that tend to have local or domestic politics that make them willing to do more. Such nations have already acted in such a way as to create renewable infrastructure, and a speedy ramp up in reliance on renewables, this is often because these are nations where concern about climate change is the greatest, and there is substantial domestic support for concerted action to mitigate climate change.

Another advantage of the EPA approach, and perhaps its greatest, is that it encourages the largest emissions reductions where they are cheapest to achieve, and in that sense promotes cost-effectiveness and helps contain the overall costs of climate change mitigation. To some extent a cap and trade regime, and even more so, a carbon tax regime, would achieve the same end of encouraging the biggest bang for the buck (or euro or ... ) in terms of emissions reduction. The EPA plan envisions some emissions trading, which is legally controversial. To the extent, in the international context, neither cap and trade nor a carbon tax are politically feasible, or can only be implemented in part, EPA's equal cost approach could be the best available alternative to encourage the most cost-effective climate change mitigation.

\section{Disadvantages of a Switching Costs Approach}

One disadvantage of a switching costs approach is that it is based on predicted costs of emissions reductions, and such predictions require a large amount of data that might not be accurate. Indeed, a number of stateslike New Jersey-and industry groups have argued that EPA's cost projections are faulty. On the other hand, emissions reduction percentage regimes of all sorts require an understanding of emissions baselines, and as the EU learned, estimates of such baselines require a great deal of information and can be inaccurate. In any regime, collecting and analyzing the needed data will not be straightforward and will require refinements.

The more persuasive criticism of the EPA approach is the one leveled by New Jersey, as discussed supra: that it creates perverse incentives by potentially assigning states that create clean power infrastructure higher emissions reduction targets than states that declined to make such investments. Under the EPA approach, a State might choose not to make "voluntary" clean power investments because it would not want EPA to respond by imposing upon the State additional emissions reduction obligations that may be more than or on a faster and less flexible timetable than the State otherwise would adopt on its own. Of course, as stated, states that 
are leaders in clean power investments might be exactly those states that, as a political matter, are open to strong EPA climate policies and that will continue to invest in cleaner power even if it is understood that stricter EPA emissions reduction targets will result. California might be one such state. Political economy and politics in each State vary, thus it is difficult to judge the robustness of the perverse incentives argument. On the international front, it may be even more difficult to say whether a switching costs approach will lead nations to adopt a strategy of not undertaking clean power investments they otherwise would have undertaken.

However, even if the perverse incentives argument is unpersuasive in terms of predicting strategic behavior by states or nations, it has rhetorical force, and the rhetorical force can translate into less support for a switching costs approach than is needed, politically, for adoption and effective implementation. For that reason alone, it is worth asking how a switching costs approach could be configured to mitigate the perverse incentives objection to it. Indeed, we see the shift between the proposed EPA rule and the final one as, in part, an effort to do just that.

\section{Mitigating Perverse Incentives}

One way that any perverse incentives created by the EPA approach can be mitigated is by structuring targets so that they reward a state or nation by achieving an extent of switching ahead of time of what is required by the first round targets. So, for example, assume that in a first round the target a nation that has heavily invested in developing solar capacity is given a relatively high target because its further ramp up costs for solar are relatively low. The nation then ramps up solar even more than required to meet its target and creates low-cost opportunities for further reliance on renewables. In setting the round two target, the nation should not be penalized for in effect over-enthusiasm, so its round two target should not be ramped up to reflect that it now has even lower relative switching costs. The nation might nonetheless continue to ramp up renewable production, but the fact that it was not required to do so as part of the round two targets could be key to avoiding political charges that the regime punished the best actors. By the same token, switching costs may be reduced as a factor in second and beyond targets so as to help ensure that the states with relatively high switching costs do not intentionally continue to occupy that position as a long-term matter.

Another way to mitigate the perverse incentives implicit in EPA's approach is to use it as only part of what goes into the setting of targets. If targets are set so that switching costs is only say a forty or fifty percent factor, the extent of any perverse incentives is proportionally reduced. 
It would seem that EPA, in its final rule, took both these tacks in mitigating possible perverse incentives, although EPA did not explicitly cite perverse incentives as its motivation. In the final rule, states that develop "early" renewable capacity ahead of what their target would require receive a credit they can use against future emission reductions requirements. And in the final rule, the imposition of nationwide performance standards for coal and natural gas plants in effect reduces the economic advantages to states of not seriously considering building up renewable capacity. At the international level, it is hard to imagine the imposition of a standard floor for performance at coal and gas plants, but there might be shared commitments to certain efficiency/performance targets along with aid commitments from wealthier countries to poorer ones to help to them achieve those kinds of targets. In fact, that structure-standard or uniform commitments to performance coupled with a commitment to aid from more technologically-advanced countries to less advanced ones-is found in a number of international environmental agreements.

\section{E. The Broad View-Many Ways Differentiate}

In any workable international agreement regarding climate change, the commitments, obligations and entitlements of nations may need to be differentiated in order to achieve agreement and make the agreement workable in practice. The circumstances of all the nations of the world, after all, are extremely varied - far more varied than the circumstances of the states in the United States. As one academic commentator recently concluded:

The point is that there will not be one type of differentiation that 'fits all' and covers all the very different circumstances and situations of parties. It will be the right combination or ' $\mathrm{mix}$ ' of substantive commitments, incentive structures, entitlements, procedural requirements, etc., which will be crucial for the success of a new agreement. A well designed and fine-tuned 'catalogue' of options (with differing commitments or entitlements) which parties can choose from upon signature or ratification might be a feasible way forward, reflecting the diversities of a globalized and interconnected world in the sophisticated design of a comprehensive agreement. 78

78. Geir Ulfstein \& Christina Voigt, Rethinking The Legal Form AND PrinCiPLes of a New Climate Agreement 195 (Univ. of Olso Faculty of Law Legal Studies ed. 2015-21), http://poseidon01.ssrn.com/delivery.php?ID=84910212606910812409303108409 5001113010088090031071033011098089124117012101124018113029120024106118 02211308809408209200007509802902609103607409201609302711612210807106 
What the EPA approach to switching costs highlights is one useful way to differentiate among participants to a climate change agreement, namely, differentiation based on the relative magnitude of switching costs each nation faces. In that way, the EPA approach offers guidance for the construction of an international accord that was not previously a focus of either commentary or an actual international accord. 